\title{
Eficiência de dois fosfatos naturais farelados em função do tamanho da partícula
}

\author{
Efficiency of two natural phosphates \\ affected by particle size
}

Nelson Horowitz ${ }^{1}$ Egon José Meurer ${ }^{2}$

\section{RESUMO}

Este trabalho foi realizado com objetivo de relacionar o tamanho da particula de dois fosfatos naturais com seu indice de eficiência agronômica (IEA) para fósforo acumulado em plantas de milho, em dois cultivos sucessivos, sem revolvimento do solo, em casa de vegetação, num LATOSSOLO VERMELHO Distrófico típico corrigido para pH 5,5. As fontes de fosfatos naturais utilizadas foram o fosfato de Gafsa e o fosfato de Gantour Black, com os seguintes tamanhos de particulas: a) $<0,074 \mathrm{~mm}$, b) de 0,074 a 0,149mm, c) de 0,149 a 0,297mm,d) de 0,297 a $0,71 \mathrm{~mm}$, e) de 0,71 a 1,41 mm, f) >1,41 mm e g) farelados, em que mais de $80 \%$ das particulas tinham tamanho entre 0,074 e 0,5mm. O superfosfato triplo, com grânulos entre 2 e $4 \mathrm{~mm}$, foi utilizado como fonte padrão comparativa de fósforo. No primeiro cultivo, os fosfatos naturais finamente moídos $(<0,074 \mathrm{~mm})$ apresentaram maior IEA; à medida que aumentou o tamanho das partículas diminuiu o IEA dos fosfatos naturais, entretanto, partículas com tamanho até $0,297 \mathrm{~mm}$ foram reativas. No segundo cultivo, o IEA para partículas com tamanho entre 0,149 e 0,71 mm, aumentou e o IEA dos fosfatos naturais farelados foi pouco reduzido em relação aos finamente moídos $(<0,074 \mathrm{~mm})$. Partículas maiores do que $0,71 \mathrm{~mm}$ não reagiram durante os dois cultivos. Os fosfatos naturais na forma fisica farelada mantiveram IEA próximo a $40 \%$ nos dois cultivos do milho. O fosfato natural de Gafsa foi mais eficiente do que o fosfato de Gantour Black no suprimento de fósforo no crescimento inicial de plântulas de milho.

Palavras-chave: fósforo, indice de eficiência agronômica, fontes de fósforo

\begin{abstract}
This study was carried out with the objective of relating the size of the particles of two natural rock phosphates with their relative agronomic efficiency (RAE), for corn in two successive growth, without revolving the soil, in greenhouse, in an oxisol, corrected for $\mathrm{pH}$ 5.5. The sources of natural phosphates were the Gafsa and the Gantour Black rock phosphates, with the following sizes of particle: a) $<0.074 \mathrm{~mm}$, b) of 0.074 to $0.149 \mathrm{~mm}$, c) of $0.149 \mathrm{~mm}$ to $0.297 \mathrm{~mm}$, d) of 0.297 to $0.71 \mathrm{~mm}$, e) of 0.71 to $1.41 \mathrm{~mm}, \mathrm{f})>1.41 \mathrm{~mm}$ and $\mathrm{g}$ ) as received, in which more than $80 \%$ of the particles presented the size between 0.074 and $0.5 \mathrm{~mm}$. The triple superphosphate with granules between 2 and $4 \mathrm{~mm}$ was used as standard. For the first crop, the finely grounded $(<0.074 \mathrm{~mm})$ presented a higher RAE than all the other particle sizes, including, as received form. While the particle size increased, the RAE of the rock phosphates decreased, however, particles up to $0.297 \mathrm{~mm}$ reacted. For the second crop, the RAE increased with the size of
\end{abstract}

\footnotetext{
${ }^{1}$ Aluno do Curso de Pós-graduação em Ciência do Solo do Programa de Pós-graduação em Agronomia da Faculdade de Agronomia da Universidade Federal do Rio Grande do Sul (UFRGS). C.P 776, 90001-970, Porto Alegre, RS. E-mail:nelsontz@terra.com.br.

${ }^{2}$ Professor do Departamento de Solos da Faculdade de Agronomia da UFRGS. Bolsista do CNPq. C.P 776, 90001-970, Porto Alegre, RS. E-mail: ejmeurer@terra.com.br 
the particles between 0.149 and $0.71 \mathrm{~mm}$. Particles with the size more than $0.7 \mathrm{~mm}$ did not react during the two crops. For the second crop, the RAE of the rock phosphate as received form, was not strongly reduced in comparison to the finely grounded $(0.074 \mathrm{~mm})$ phosphates. The rock phosphates as received form maintained the $R A E$ around $40 \%$ in the two corn crops. The Gafsa rock phosphate was more efficient than the Gantour Black to supply phosphorus in initial growth of corn plants.

Key words: phosphorus, index of relative agronomic efficiency, phosphorus sources.

\section{INTRODUÇÃO}

A granulação dos fosfatos naturais, devido aos inconvenientes da sua aplicação na forma de pó, provocou significativa redução na sua eficiência agronômica, resultando no seu desaparecimento do mercado nacional. Nos últimos anos, os fosfatos naturais na forma de "farelados" voltaram a ser oferecidos no mercado brasileiro. Estes apresentam cerca de $80 \%$ de suas partículas com tamanhos entre $0,074 \mathrm{~mm}$ e $0,50 \mathrm{~mm}$.

Os fosfatos naturais têm baixa solubilidade em água, e assim, quanto menor o tamanho da partícula e maior o contato com o solo, maior será a liberação de fósforo (RAIJ, 1991). Trabalhos demonstraram que o fosfato natural de Gafsa, moído até que $85 \%$ de suas partículas ficassem menores do que $0,074 \mathrm{~mm}$, apresentou resultados próximos ao superfosfato triplo granulado, mesmo nos primeiros cultivos (ABRÃO et al., 1980; GOEDERT \& LOBATO, 1980; GOEPFERT \& TEDESCO, 1986; BRAGA et al., 1991). Há poucos estudos comparativos entre a eficiência agronômica de fosfatos naturais moídos e os na forma de farelados. A moagem de fosfatos naturais para obtenção de partículas menores do que $0,15 \mathrm{~mm}$, para aumentar sua eficiência, raramente se justifica, pois o incremento na superfície de contato seria de apenas 5\% do total, devido à alta porosidade do material (LEHR \& MCCLELLAN, 1972; HAMMOND, 1978; KHASAWNEH \& DOLL, 1978; MARWAHA, 1989).

Em solo de Cerrado, REIN et al. (1994) mostraram que o fosfato natural reativo de Carolina do Norte moído ( $85 \%$ das partículas menores do que $0,074 \mathrm{~mm}$ ) teve eficiência equivalente ao superfosfato triplo e maior do que o mesmo fosfato natural na forma farelada ( $80 \%$ das partículas entre 0,15 e $0,3 \mathrm{~mm})$ somente no primeiro plantio de soja; porém, no segundo e terceiro plantios, o fosfato natural na forma farelada, superou as demais fontes. Fosfatos naturais farelados de Arad, Marrocos e Gafsa apresentaram resultados similares ao superfosfato triplo granulado já no primeiro culti de milho em solos do Cerrado (KORNDORFER et al., 1997). Em cinco diferentes solos da Malásia, em experimentos de campo, o fosfato natural de Carolina do Norte teve a mesma eficiência tanto moído ( $85 \%$ das partículas menores do que $0,074 \mathrm{~mm}$ ) quanto na forma farelada, em cultivos com vários cereais, demonstrando não haver necessidade de maior grau de moagem para fosfatos naturais de alta reatividade (CHIEN \& FRIESEN, 1992).

Este estudo foi realizado com objetivo de avaliar como o tamanho da partícula de dois fosfatos naturais farelados pode afetar o suprimento de fósforo no crescimento inicial de plantas de milho, tendo em vista que a moagem mais apurada destes produtos acresce custos ao produto final, dificulta sua manipulação e nem sempre se traduz em acréscimos nos rendimentos das culturas.

\section{MATERIAL E MÉTODOS}

O trabalho constou de dois cultivos em vasos, conduzidos em casa de vegetação do Departamento de Solos da Faculdade de Agronomia da Universidade Federal do Rio Grande do Sul, nos anos 1995 e 1996. Foram usadas amostras superficiais $(0-20 \mathrm{~cm})$ de um LATOSSOLO VERMELHO Distrófico típico do estado do Rio Grande do Sul, proveniente do Município de Marau. As amostras de solo foram secas ao ar e passadas em peneiras de $2 \mathrm{~mm}$ de abertura. A análise deste solo registrou os seguintes resultados: argila, $380 \mathrm{~g} \mathrm{~kg}^{-1} ; \mathrm{pH}$ em água, 5,0; índice SMP, 5,1; fósforo extraível, 3mg $\mathrm{kg}^{-1}$; potássio extraível, $110 \mathrm{mg} \mathrm{kg}^{-1}$; matéria orgânica, $38 \mathrm{~g}$ $\mathrm{kg}^{-1}$; alumínio trocável, $8 \mathrm{mmol}_{\mathrm{c}} \mathrm{kg}^{-1}$; cálcio trocável, $21 \mathrm{mmol}_{\mathrm{c}} \mathrm{kg}^{-1}$; magnésio trocável. $12 \mathrm{mmol}_{\mathrm{c}} \mathrm{kg}^{-1}$; enxofre, 19,5 $\mathrm{mg} \mathrm{kg}^{-1}$; zinco, 4,9mg kg${ }^{-1}$; cobre, $13,9 \mathrm{mg} \mathrm{kg}^{-1}$; boro $0,4 \mathrm{mg} \mathrm{kg}^{-1}$; manganês, $99 \mathrm{mg} \mathrm{kg}^{-1}$. Os procedimentos usados para estas análises estão apresentados em TEDESCO et al. (1995).

Baseado em trabalho preliminar, o solo recebeu mistura, na relação $3: 1$, de carbonato de cálcio (3 partes) com carbonato de magnésio (1 parte) em quantidade necessária para elevar o $\mathrm{pH}$ em água para 5,5. Deixou-se o solo reagir com os carbonatos por 30 dias, em sacos plásticos, durante os quais era revolvido a cada cinco dias. A cada sete dias mediu-se o $\mathrm{pH}$ em água até que ocorresse sua estabilização em 5,5, o que aconteceu ao redor de 20 dias após a calagem. Após o período de incubação, efetuou-se adubação básica com 100 $\mathrm{mg} \mathrm{kg}^{-1}$ de solo de $\mathrm{N}$ e K. As fontes utilizadas para estes nutrientes foram, respectivanmente, o sulfato de amônio e o cloreto de potássio.

Os tratamentos, com três repetições, constaram da aplicação de dois fosfatos naturais reativos, 
em diferentes tamanho de partículas, misturados uniformemente às amostras do solo, previamente seco, na dose de $190 \mathrm{mg}^{\text {de }} \mathrm{P} \mathrm{kg}^{-1}$ de solo, quantidade que produziu $80 \%$ do rendimento máximo de matéria seca do milho em estudo preliminar neste LATOSSOLO VERMELHO Distrófico típico (curva de resposta, utilizando-se como fonte de $\mathrm{P}$ o superfosfato triplo). A produção de matéria seca do milho e a quantidade de fósforo acumulado na parte aérea das plantas, obtidos nestes tratamentos, foram comparados com os obtidos em dois tratamentos adicionais que fizeram parte do experimento: uma testemunha (sem fósforo) e um tratamento com superfosfato triplo granulado (grânulos com diâmetro entre 2 e $4 \mathrm{~mm}$ ). As fontes de fósforo utilizadas foram o fosfato de Gafsa com $29 \%$ de $\mathrm{P}_{2} \mathrm{O}_{5}$ total e com $10 \%$ de $\mathrm{P}_{2} \mathrm{O}_{5}$ solúvel em ácido cítrico a 2 dag $\mathrm{L}^{-1}$ $1: 100$, e o fosfato de Gantour Black com $30,5 \%$ de $\mathrm{P}_{2} \mathrm{O}_{5}$ total e $8,8 \%$ de $\mathrm{P}_{2} \mathrm{O}_{5}$ solúvel em ácido cítrico a 2 dag $\mathrm{L}^{-1}, 1: 100$ e o superfosfato triplo com $46 \%$ de $\mathrm{P}_{2} \mathrm{O}_{5}$ solúvel em citrato neutro de amônio + água e com $42 \%$ de $\mathrm{P}_{2} \mathrm{O}_{5}$ solúvel em água. $\mathrm{O}$ tamanho das partículas dos fosfatos naturais utilizados foram: a) < $0,074 \mathrm{~mm}$; b) entre 0,074 e $0,149 \mathrm{~mm}$; c) entre 0,149 e $0,297 \mathrm{~mm}$; d) entre 0,297 e $0,71 \mathrm{~mm}$; e) entre 0,71 e $1,41 \mathrm{~mm}, \mathrm{f})>1,41 \mathrm{~mm}$ e g) farelados. Os diferentes tamanhos de partículas utilizadas no estudo foram obtidos a partir da moagem das amostras dos fosfatos naturais farelados e peneiragem nas malhas correspondentes. Os fosfatos na forma física farelada tinham os seguintes perfis granulométricos: fosfato de Gafsa: $94,1 \%>0,074 \mathrm{~mm}, 63,8 \%>0,149 \mathrm{~mm}, 26,8 \%$ $>0,297 \mathrm{~mm}, 17,9 \%>0,5 \mathrm{~mm}, 9,26 \%>1 \mathrm{~mm}$ e $3,03 \%$ $>2 \mathrm{~mm}$; fosfato de Gantour Black: 97,6\%>0,074mm, $85,3 \%>0,149 \mathrm{~mm}, 23,7 \%>0,297 \mathrm{~mm}, 9,0 \%>0,5 \mathrm{~mm}$, $5,56 \%>1 \mathrm{~mm}$ e $3,23 \%>2 \mathrm{~mm}$.

Após a aplicação dos tratamentos, os solos foram colocados em vasos plásticos, perfurados com seis orifícios no fundo com o objetivo de permitir drenagem livre da água, seguindo metodologia sugerida por HANAFI et al. (1992). No fundo dos vasos, que tinham capacidade de 10 litros, colocou-se $2,5 \mathrm{~kg}$ de brita e acima desta, uma tela plástica com pequenos furos, que tinham a função de separar a brita do solo.

Foram realizados dois cultivos com milho (Pionner 3072), pré-germinadas em papel filtro. Em cada cultivo, podou-se a raiz, deixando-se com três centímetros de comprimento e transplantaram-se oito plantas por vaso. Após cinco dias, fez-se desbaste, deixando-se quatro plantas uniformes por vaso. Ao longo dos cultivos, a umidade do solo foi ajustada para $80 \%$ da capacidade de campo do solo adicionando-se água destilada a cada vez que o teor de umidade diminuiu. Entre os dois cultivos não houve revolvimento do solo.
No segundo cultivo, antes do transplante das plântulas de milho, adicionou-se, ao solo seco, de cada vaso, na forma de solução de $\mathrm{NH}_{4} \mathrm{NO}_{3} \mathrm{e} \mathrm{KCl}, 100 \mathrm{mg} \mathrm{kg}^{-1}$ de solo de $\mathrm{N}$ e $100 \mathrm{mg} \cdot \mathrm{kg}^{-1}$ de solo de K. Nos dois cultivos, aos 21 dias após o transplante, as plantas de milho foram cortadas rente à superfície do solo. O material colhido foi colocado em sacos de papel e secado em estufa a $60^{\circ} \mathrm{C}$. Após atingir peso constante, o material foi pesado e analisado. O primeiro plantio foi realizado em 17/11/95 e o segundo em 29/01/96. Na parte aérea das plantas, foi determinado o teor de fósforo conforme metodologia descrita em TEDESCO et al. (1995).

A avaliação da eficácia dos fosfatos naturais no suprimento de fósforo às plantas de milho foi feita utilizando-se o índice de eficiência agronômica (IEA) para fósforo absorvido na parte aérea do milho, sendo: IEA $=\left(y_{2}-y_{1}\right) /\left(y_{3}-y_{1}\right)$ onde, $y_{2}=$ fósforo acumulado na parte aérea no tratamento com fosfato natural; $y=$ fósforo acumulado na parte aérea no tratamento testemunha, $\mathrm{y}_{3}=$ fósforo acumulado na parte aérea no tratamento com superfosfato triplo (valor de referência)

Para a análise estatística dos resultados (contrastes e regressão), consideraram-se os fosfatos naturais como fatores (2), o tamanho da partícula como níveis (7) e os tratamentos testemunha e superfosfato triplo como adicionais ao fatorial.

\section{RESULTADOS E DISCUSSÃO}

A capacidade de os fosfatos naturais testados suprirem fósforo foi avaliada, em dois cultivos em casa de vegetação, pela quantidade de fósforo acumulado na parte aérea das plantas e pelo IEA. A análise estatística indicou efeito significativo para os dois fosfatos naturais testados e para o tamanho da partícula. Não houve efeito para a interação fontes de fosfatos versus tamanho da partícula.

No primeiro cultivo, no tratamento testemunha, sem fósforo, a quantidade acumulada do nutriente na parte aérea das plantas foi de $1,97 \mathrm{mg} \mathrm{vaso}^{-1} \mathrm{de} \mathrm{P}$ e os maiores acúmulos de fósforo foram obtidos com o superfosfato triplo $\left(12,69 \mathrm{mg} \mathrm{vaso}^{-1}\right)$; com os fosfatos naturais foram obtidos com menores tamanho de partículas (Tabela 1). No segundo cultivo, igualmente, as maiores quantidades de fósforo acumuladas na parte aérea das plantas ocorreram com o superfosfato triplo e com os fosfatos naturais finamente moídos. As quantidades supridas, porém, foram menores que aquelas do primeiro cultivo, o que pode ser atribuído às prováveis reações de adsorção do fósforo no solo utilizado neste estudo.

Tanto no primeiro como no segundo cultivo, observou-se um pronunciado efeito do tamanho da partícula na capacidade de suprimento de fósforo dos 
fosfatos naturais: houve uma acentuada redução na quantidade de fósforo acumulado na parte aérea das plantas à medida que aumentou o tamanho das partícula (Figuras 1 e 2). Os fosfatos naturais finamente moídos (partículas $<0,074 \mathrm{~mm}$ ) produziram resultados semelhantes, no primeiro cultivo, aos obtidos com a aplicação do superfosfato triplo granulado, enquanto que aqueles com partículas maiores do que $0,297 \mathrm{~mm}$ produziram resultados próximos ou semelhantes aos da testemunha. A perda da eficiência de fosfatos naturais com maiores tamanhos de partícula, também foi observada por BARRETO et al. (1977) e ABRÃO et al. (1980).

O acúmulo de fósforo na parte aérea das plantas resultantes da aplicação dos fosfatos naturais na forma de farelados, foi superior ao da testemunha, indicando que os fosfatos, nesta forma, também podem suprir fósforo às plantas. No primeiro cultivo, os fosfatos naturais na forma de farelados produziram resultados equivalentes àqueles com partículas com tamanhos entre 0,149 e $0,297 \mathrm{~mm}$ e, foram mais eficientes, nos dois cultivos, do que aqueles com partículas com tamanho superior a $0,297 \mathrm{~mm}$ (Tabela 1). Estes resultados concordam com a afirmação de que o efeito de tamanho da partícula é significativo, e que o efeito do grau de moagem é importante para aumentar a área de contato das partículas do fosfato natural com o solo, com objetivo de proporcionar uma liberação mais rápida do fósforo (KHASAWNEH \& DOLL, 1978; CHIEN \& FRIESEN, 1992). Porém, os resultados não concordam com a afirmação, para o primeiro plantio em condições de casa de vegetação, de que não seria necessário moer os fosfatos naturais em partículas menores do que $0,149 \mathrm{~mm}$ (JONES, 1975; KHASAWNEH \& DOLL, 1978; CHIEN \& MENON, 1995). A similaridade dos resultados obtidos com as partículas mais finas $(<0,074 \mathrm{~mm})$ dos fosfatos naturais, quando misturados ao volume total do solo, com os obtido com o superfosfato triplo granulado no primeiro cultivo, concorda com os resultados obtidos por vários autores (DYNIA, 1977; ABRÃO et al., 1980; GOEDERT \& LOBATO, 1980; GOEPFERT \& TEDESCO, 1986; BRAGA et al., 1991; REIN, 1994).

O efeito do tamanho da partícula na eficiência dos fosfatos naturais nos dois cultivos, é melhor vo), à medida que aumentou o tamanho da partícula,

Tabela 1 - Fósforo acumulado na parte aérea de plântulas de milho, em dois cultivos em casa de vegetação, em função das fontes de fósforo e do tamanho da partícula (médias de três repetições).

\begin{tabular}{|c|c|c|c|c|}
\hline Tratamento & Tamanho da partícula & Cultivo 1 & Cultivo 2 & Total \\
\hline & $\mathrm{mm}$ & \multicolumn{3}{|c|}{ 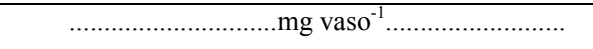 } \\
\hline Testemunha & - & $1,97 \mathrm{aG}$ & $1,58 \mathrm{aF}$ & 3,55 \\
\hline Superfosfato triplo & $2-4$ & $12,69 \mathrm{aA}$ & $8,67 \mathrm{bA}$ & 21,36 \\
\hline \multicolumn{5}{|c|}{ Superfosfato triplo aplicado no $2^{\underline{o}}$ plantio } \\
\hline & $2-4$ & - & 14,75 & - \\
\hline Gafsa & $<0,074$ & $11,94 \mathrm{aA}$ & $5,56 \mathrm{bB}$ & 17,50 \\
\hline Gafsa & $0,074-0,149$ & $8,19 \mathrm{aC}$ & $5,84 \mathrm{bB}$ & 14,03 \\
\hline Gafsa & $0,149-0,297$ & $5,48 \mathrm{aE}$ & $5,80 \mathrm{aB}$ & 11,28 \\
\hline Gafsa & $0,297-0,71$ & $3,01 \mathrm{aFG}$ & $3,80 \mathrm{aCD}$ & 6,81 \\
\hline Gafsa & $0,71-1,41$ & $2,56 \mathrm{aFG}$ & $2,42 \mathrm{aEF}$ & 4,98 \\
\hline Gafsa & $>1,41$ & $2,13 \mathrm{aFG}$ & $1,73 \mathrm{aF}$ & 3,86 \\
\hline Gafsa & Farelado & $6,52 \mathrm{aDE}$ & $4,66 \mathrm{bBC}$ & 11,18 \\
\hline Gantour Black & $<0,074$ & $9,98 \mathrm{aB}$ & $3,74 \mathrm{bCD}$ & 13,72 \\
\hline Gantour Black & $0,074-0,149$ & $7,05 \mathrm{aD}$ & $4,15 \mathrm{bCD}$ & 11,20 \\
\hline Gantour Black & $0,149-0,297$ & $5,34 \mathrm{aE}$ & $4,54 \mathrm{aBC}$ & 9,88 \\
\hline Gantour Black & $0,297-0,71$ & $3,36 \mathrm{aF}$ & $3,26 \mathrm{aDE}$ & 6,62 \\
\hline Gantour Black & $0,71-1,41$ & $2,65 \mathrm{aFG}$ & $2,50 \mathrm{aEF}$ & 5,15 \\
\hline Gantour Black & $>1,41$ & $2,16 \mathrm{aFG}$ & $1,77 \mathrm{aF}$ & 3,93 \\
\hline Gantour Black & Farelado & $5,37 \mathrm{aE}$ & $4,10 \mathrm{bCD}$ & 9,47 \\
\hline
\end{tabular}

Letras minúsculas iguais não diferenciam médias entre cultivos pelo teste de Duncan a 5\%.

Letras maiúsculas iguais não diferenciam médias dentro do mesmo cultivo pelo teste de Duncan a 5\%. 


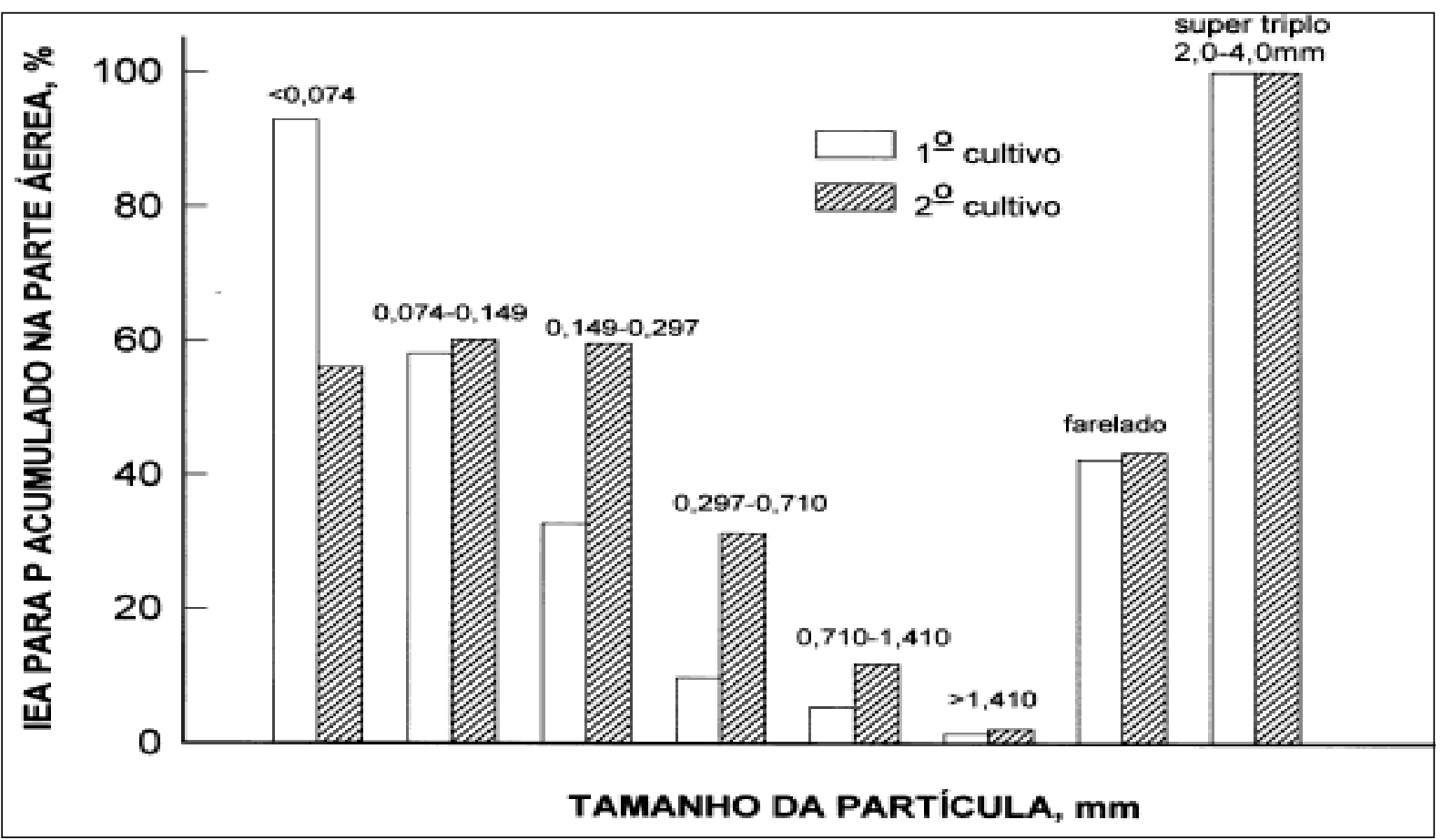

Figura 1 - Índice de eficiência agronômica (IEA) para fósforo acumulado na parte aérea de plântulas de milho, aos 21 dias de crescimento em dois cultivos em casa de vegetação, em função do tamanho da partícula do fosfato natural de Gafsa.

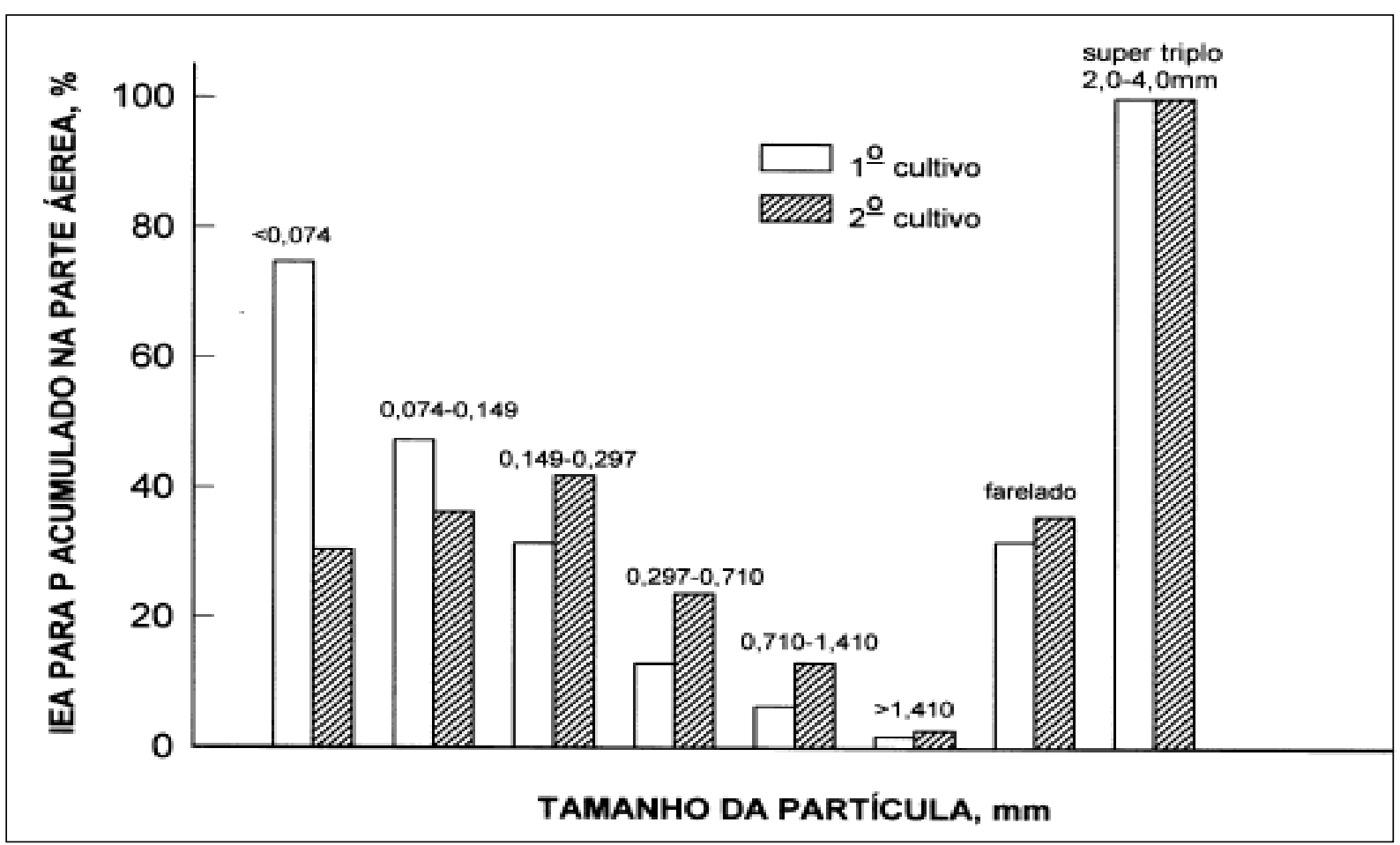

Figura 2 - Índice de eficiência agronômica (IEA) para fósforo acumulado na parte aérea de plântulas de milho, aos 21 dias de crescimento, em dois cultivos em casa de vegetação, em função do tamanho da partícula do fosfato natural Gantour Black.

Ciência Rural, v. 33, n. 1, jan-fev, 2003. 
visualizado pela análise dos índices de eficiência agronômica (IEA) apresentados nas figuras 1 e 2 . De uma maneira geral, para o efeito imediato (primeiro cultivo), à medida que aumentou o tamanho da pqrtícula, houve uma redução na eficiência dos fosfatos. Porém, a partir do segundo cultivo, as partículas mais grosseiras, até $0,71 \mathrm{~mm}$, aumentaram seus IEA para o fósforo acumulado na parte aérea das plantas. Estes resultados concordam com os obtidos por CHIEN \& FRIESEN (1992) que afirmam que, com o passar do tempo, o efeito do tamanho da partícula dos fosfatos naturais tendem a desaparecer. Os fosfatos finamente moídos com partículas menores do que $0,074 \mathrm{~mm}$, tiveram sua eficiência significativamente reduzida no segundo cultivo: no fosfato de Gafsa foi reduzida de $93 \%$ para $58 \%$ e no de Gantour Black de $75 \%$ para $30 \%$.Para o super-fosfato triplogranulado adicionado no primeiro cultivo, o mesmo efeito foi constatado, refletindo-se na quantidade de fósforo acumulado nas plantas. Isto ocorreu devido a reações de absorção do fósforo no solo. No caso dos fosfatos naturais, pela maior área de contato das partículas finamente moídas com o solo, e no caso do superfosfato triplo, pela sua elevada solubilidade em água.

Os resultados obtidos no segundo cultivo do milho destacam a reatividade das partículas dos fosfatos com tamanhos entre 0,149 e $0,297 \mathrm{~mm}$ e aquelas com tamanhos entre 0,297 e 0,71 mm (Figuras 1 e 2). Para as primeiras, o IEA praticamente duplicou no segundo cultivo do milho, aumentando de pouco mais de $30 \%$ para $60 \%$, no caso do fosfato de Gafsa, e para $42 \%$ no caso do Gantour Black. Para as segundas, o IEA aumentou de $10 \%$, aproximadamente, para valores entre 24 e $31 \%$, no segundo cultivo, respectivamente, para o fosfato de Gantour Black e para o fosfato de Gafsa.

Os resultados obtidos com os fosfatos naturais na forma farelada indicaram que estes produtos, quando comparados às formas em que foram finamente moídos $(<0,074 \mathrm{~mm})$, foram menos eficientes. Entretanto, não se pode deixar de considerar que os fosfatos naturais na forma farelada poderão ser uma fonte alternativa mais barata de fósforo. Com efeito, ambos os fosfatos, na forma farelada, proporcionaram quantidades de fósforo acumuladas na parte aérea das plantas significativamente superiores ao tratamento testemunha (Tabela 1). O IEA para o fosfato de Gafsa farelado manteve-se em torno de $42 \%$ nos dois cultivos do milho e o IEA dos fosfato farelado de Gantour Black foi de $32 \%$ no primeiro cultivo do milho e de $37 \%$ no segundo.

Os resultados obtidos neste trabalho também mostraram que o fosfato natural de Gafsa foi su- perior ao fosfato natural de Gantour Black, proporcionando maior acumulado de fósforo na parte aérea das plantas para a maioria dos tamanhos de partículas investigados (Tabela 1). O fosfato de Gafsa na forma farelada, pela maior reatividade das suas partículas, igualmente apresentou maior índice de eficiência agronômica que o fosfato Gantour Black. A diferença na eficiência destes fosfatos está provavelmente ligada ao grau de substituição isomórfica do fósforo por outros íons na rede cristalina, pois a reatividade do fosfato natural sedimentar é proporcional ao seu grau de substituição isomórfica (LEHR \& MCCLELLAN, 1972; KHASAWNEH \& DOLL, 1978; ANDERSON et al., 1985).

\section{CONCLUSÕES}

1. O fosfatos naturais apresentaram o maior índice de eficiência agronômica (IEA) para o milho quando foram moídos finamente (partículas $<0,074 \mathrm{~mm})$.

2. À medida que aumentou o tamanho das partículas, diminuiu o IEA dos fosfatos naturais; entretanto, partículas com tamanho até $0,297 \mathrm{~mm}$ mostraram-se reativas produzindo uma quantidade de fósforo acumulado na parte aérea das plantas de milho superiores à testemunha sem fósforo.

3. Os IEA dos fosfatos naturais finamente moídos $(<0,074 \mathrm{~mm})$ diminuíram do primeiro para o segundo cultivo; o IEA das partículas com tamanho superior a $0,149 \mathrm{~mm}$ aumentou do primeiro para o segundo cultivo. Partículas maiores do que $0,71 \mathrm{~mm}$ não foram reativas.

4. Os fosfatos naturais na forma de farelados apresentaram um IEA entre $32 \%$ e $42 \%$ no primeiro cultivo e entre $37 \%$ e $43 \%$ no segundo cultivo.

5. O fosfato de Gafsa foi mais eficiente do que o fosfato de Gantour Black em suprir fósforo para as plantas do milho.

\section{REFERÊNCIAS BIBLIOGRÁFICAS}

ABRÃO, J.R.; KORNDÖRFER, G.; VOLKWEISS, S. J. Efeito da granulação, do modo de aplicação e de misturas de fosfatos naturais com o superfosfato triplo no rendimento das culturas. In: REUNIÃO DE PESQUISA DE SOJA DA REGIÃO SUL, 8., 1980, Cruz Alta. Anais... Cruz Alta,RS : FECOTRIGO, 1980. v.5. p.163-169.

ANDERSON, D.L.; KUSSOW, W.R.; COREY, R.B. Phosphate rock dissolution in soil: indications from plant growth studies. Soil Science Society of America Journal, Madison, v.49, p.918-925, 1985.

BRAGA, N.R. et al. Eficiência agronômica de nove fosfatos em quatro cultivos consecutivos de soja. Revista Brasileira de Ciência do Solo, Campinas, v.15, p.315-319, 1991. 
CHIEN, S.H.; FRIESEN, D.K. Phosphate rock for direct application. In: SIKORA, F.J. (ed). Future directions for agricultural phosphorus research. Muscle Shoals : International Fertilizer Development Center, 1992. p.47-52. (TVA Bulletin Y224)

GOEDERT, W.J.; LOBATO, E. Eficiência agronômica de fosfatos em solo de cerrado. Pesquisa Agropecuária Brasileira, Brasília, v.15, p.311-318, 1980 .

GOEPFERT, C.F.; TEDESCO, A. Efeito de fontes, níveis de fósforo e granulometria de fosfatos naturais sobre o rendimento de grãos de colza e de soja. Agronomia Sulriograndense, Porto Alegre, v.22, p.53-59, 1986.

HAMMOND, L.L. Agronomic measurements of phosphate rock effectiveness. In: SEMINAR OF PHOSPHATE ROCK FOR DIRECT APLLICATION, 1978, Haifa. Phosphate rock for direct application... Muscle Shoals : International Fertilizer Development Center, 1978. p.147-157. (Special Publication IFDC-S-1).

HANAFI, M.M.; SYERS, J.K.; BOLAN, N.S. Leaching effect on the dissolution of two phosphate rocks in acid soils. Soil Science Society of America Journal, Madison, v.56, p.1325-1330, 1992.

KHASAWNEH, F.E.; DOLL, E.C. The use of phosphate rock for direct application to soils. Advances in Agronomy, v.30, p.159206, 1978.
KORNDÖRFER, G.H.; CABEZAS, W.A.L.; HOROWITZ, N. Eficiência agronômica de fosfatos naturais estrangeiros na cultura do milho. In: XXVI CONGRESSO BRASILEIRO DE CIÊNCIA DO SOLO, 1997, Rio de Janeiro, RJ. Resumos... Rio de Janeiro : Sociedade Brasileira de Ciência do Solo, 1997. p. 145 .

LEHR, J.R, McCLELLAN, G.H. A revised laboratory reactivity scale for evaluating phosphate rocks for direct application. Muscle Shoals : National Fertilizer Development Center, 1972. 36p. (Bulletin, Y-43).

MARWAHA, B.C. Rock phosphate holds the key to productivity in acid soils: a review. Fertilizer New, v.34, p.23-29, 1989.

RAIJ, B. van. Fertilidade do solo e adubação. São Paulo : Agronômica Ceres, 1991. 343p.

REIN, T.A.; SOUSA, D.M.G.; LOBATO, E. Eficiência agronômica do fosfato natural da Carolina do Norte em solo de cerrado. In: REUNIÃO BRASILEIRA DE FERTILIDADE DO SOLO E NUTRIÇÃO DE PlANTAS, 21., 1994, Petrolina - PE. Anais... EMBRAPA/CPATSA, 1994. p.38-40.

TEDESCO, M.J. et al.. Análises de solo, plantas e outros materiais. Porto Alegre : Departamento de Solos da Universidade Federal do Rio Grande do Sul, 1995. 174p. (Boletim Técnico, 5). 